Article

\title{
Residual Stress Differences between Uniform and Non-Uniform Heating Treatment of Bimetallic Roll: Effect of Creep Behavior on Residual Stress
}

\author{
Nao-Aki Noda ${ }^{1}$, Yoshikazu Sano ${ }^{1}$, Mohd Radzi Aridi ${ }^{1}{ }^{*}$, Kenji Tsuboi ${ }^{1}$ and Nozomu Oda ${ }^{2}$ \\ 1 Department of Mechanical Engineering, Kyushu Institute of Technology, 1-1 Sensui-cho Tobata-ku, \\ Kitakyushu-shi 804-8550, Japan; noda.naoaki844@mail.kyutech.jp (N.-A.N.); \\ sano.yoshikazu029@mail.kyutech.jp (Y.S.); q104303k@mail.kyutech.jp (K.T.) \\ 2 Technology Department, Hitachi Metals Wakamatsu Co., 1-9-1 Kitahama, Wakamatsu-ku, \\ Kitakyushu-shi 808-8558, Japan; nozomu.oda.cy@hitachi-metals.com \\ * Correspondence: radz7cr@gmail.com; Tel.: +81-93-884-3124
}

Received: 2 October 2018; Accepted: 1 November 2018; Published: 15 November 2018

\begin{abstract}
The work roll is one of the most important tools in the steel rolling industry. Work rolls are used under extremely severe conditions such as high temperature, high loading, and an aggressive atmosphere. To meet those demands, bimetallic rolls have recently been used to replace conventional single material rolls. Usually, a compressive residual stress is introduced to prevent surface cracking. However, a tensile residual stress at the center appears to balance the compressive residual stress. This center residual stress sometimes causes roll failure. In this paper, therefore, a simulation is performed using the finite element method (FEM) for the quenching process of the bimetallic roll by considering the creep behavior. Then the effect of pre-heating conditions is discussed. The results show that the maximum stress point for the tensile stress at the roll center for non-uniform heating is $24 \%$ less than that achieved with uniform heating, although the same compressive stresses appear at the surface. Then, using different work roll diameters, the center tensile residual stress for non-uniform heating is found to be smaller than the uniform heating. Also, it is found that the area ratios of the shell-core only have a small influence on the residual stress of the bimetallic roll for both heating treatments.
\end{abstract}

Keywords: work roll; element analysis; simulation; heat treatment; shell-core ratio

\section{Introduction}

In order to improve work roll performance in steel rolling industries, many studies have been conducted to investigate wear resistance, surface roughness, and center toughness [1-4]. To meet such different demands, bimetallic rolls, as shown in Figure 1, have been widely used to replace the conventional single material rolls [5]. Bimetallic rolls are manufactured by the centrifugal casting method, in which high-speed steel (HSS) is used as the shell and ductile casting iron (DCI) is used as the core (see Figure 1) [6-8].

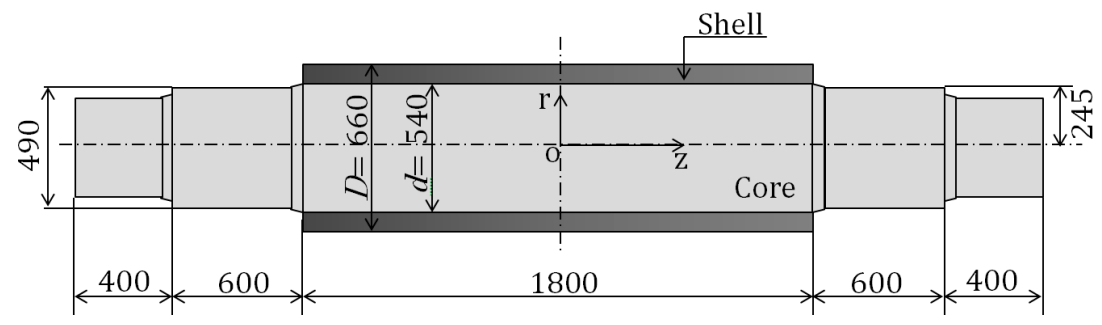

Figure 1. Model of the bimetallic roll (mm). 
Quenching heat treatment produces compressive residual stress to prevent fatigue crack at the roll outer layer [9-12]. However, to balance the compressive stress, tensile residual stress always appears at the roll center, which may cause roll fracture. Decreasing the center tensile stress is therefore desirable to reduce the risk of fracture from the roll center. Since the residual stress can be controlled by the heat treatment, an appropriate quenching process is required to improve bimetallic roll quality [13-16].

In our previous study [17-19], the usefulness of non-uniform heating treatments was explained, although the material data were not indicated at the request of the company with which we collaborated. Since the material data could not be indicated, the detailed effect of the material on the residual stress has not yet been clarified. Therefore, in this paper, the simulation will be performed under specific material data where the new materials and new roll are considered. Then, the effect of the heat treatment will be discussed clearly by applying the finite element method (FEM) to the quenching process after uniform heating and non-uniform heating. Moreover, the effects of the roll diameter and the area ratio on the residual stresses will be discussed.

\section{Mechanical Properties and Materials Data of Bimetallic Roll}

As shown in Figure 1, we assumed a composite roll with a diameter of $660 \mathrm{~mm}$, outer layer thickness of $60 \mathrm{~mm}$, and body length of $1800 \mathrm{~mm}$. In order to remove the internal stress caused by the transformation in the cooling process after casting, the roll was annealed and gradually cooled to room temperature. As a result, the residual stress was considered negligible before the heating treatment, which was held at a temperature exceeding $100{ }^{\circ} \mathrm{C}$. Even in the case of non-uniform heating, since the whole work roll was heated and then maintained at $600{ }^{\circ} \mathrm{C}$ or higher, stress-free conditions were set as the initial conditions of the analysis.

Figure 2 shows the microstructure of the outer and inner layers around the boundary layer. In the outer layer of HSS, the carbides are fine and homogeneously distributed but coarsened at the boundary. In the inner layer of DCI, the spherical graphite is surrounded by ferrite. In Figure 2, a good diffusion state is maintained at the boundary and good composite structures are seen. Table 1 shows the material properties for the outer layer of HSS and the inner layer of DCI. The outer layer HSS has a composition of Carbon (1-3\%), Silicon ( $<2 \%)$, Manganese ( $<1.5 \%)$, Phosphorus $(<1 \%)$, Sulphur $(<1 \%)$, Nickel $(<5 \%)$, Chromium (2-7\%), Molybdenum (<10\%), Cobalt $(<10 \%)$, Vanadium (3-10\%), Wolfram $(<20 \%)$ and Magnesium (<10\%). Meanwhile the inner DCI has a composition of Carbon (2.5-4\%), Silicon (1.5-3.1\%), Manganese $(<1 \%)$, Phosphorus $(<0.1 \%)$, Sulphur $(<0.1 \%)$, Nickel (0.4-5\%), Chromium $(0.01-1.5 \%)$, Molybdenum (0.1-1\%), Cobalt ( $<1 \%)$, Vanadium $(<1 \%)$, Wolfram $(<1 \%)$ and Magnesium $(0.02-0.08 \%)$ in its composition.

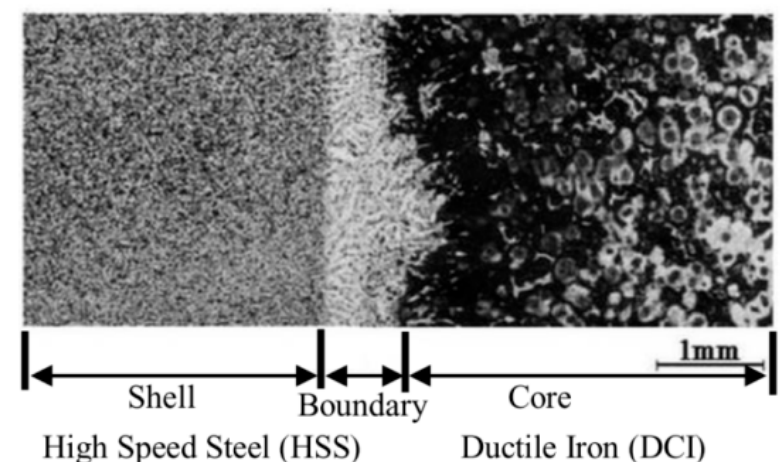

Figure 2. View of microstructure for a high-speed-steel-type roll with a ductile core. *Reproduced with permission from Noda et al., Journal of the Japan Society for Technology of Plasticity, 2018.

In our previous study [19], the material data were not indicated in detail since they constituted confidential information of the roll manufacturing company. Since the purpose of this study is to clarify the residual stress during the quenching process, all material data are provided, as shown 
in Figure 3. This figure shows the Young's modulus, specific heat, thermal conductivity, thermal expansion coefficient, Poisson's ratio, and stress-strain characteristic for both HSS and DCI during the quenching process.

Table 1. Mechanical properties of the shell and core at room temperature.

\begin{tabular}{ccc}
\hline Property & Shell & Core \\
\hline 0.2\% proof stress $(\mathrm{MPa})$ & 1270 & 410 \\
Young's modulus $(\mathrm{GPa})$ & 228 & 168 \\
Poisson's ratio & 0.3 & 0.28 \\
Density $\left(\mathrm{kg} / \mathrm{m}^{3}\right)$ & 7600 & 7300 \\
Thermal expansion coefficient $\left(\mathrm{K}^{-1}\right)$ & $12.6 \times 10^{-6}$ & $13.0 \times 10^{-6}$ \\
Thermal conductivity $(\mathrm{W} / \mathrm{m} \cdot \mathrm{K})$ & 20.2 & 23.4 \\
Specific heat $(\mathrm{J} / \mathrm{kg} \cdot \mathrm{K})$ & 0.46 & 0.42 \\
Shore hardness $(\mathrm{Hs})$ & 85 & 50 \\
\hline
\end{tabular}

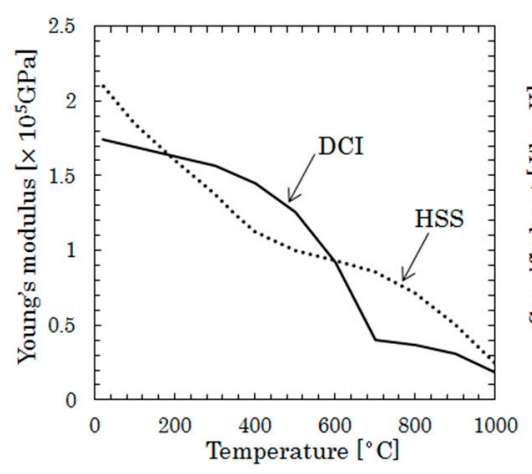

(a)

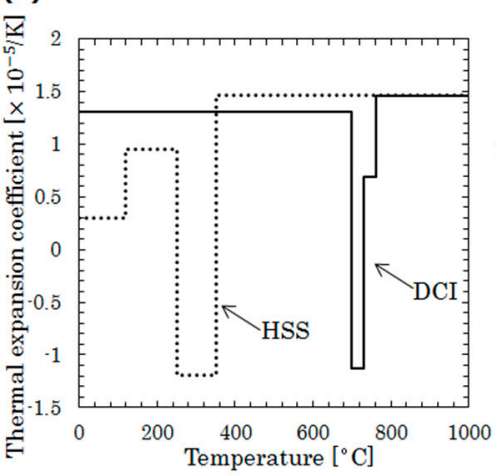

(d)

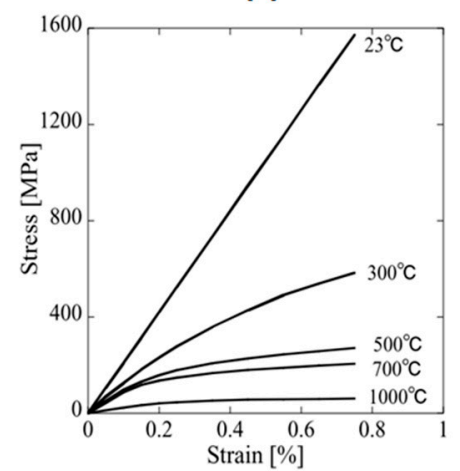

(f)

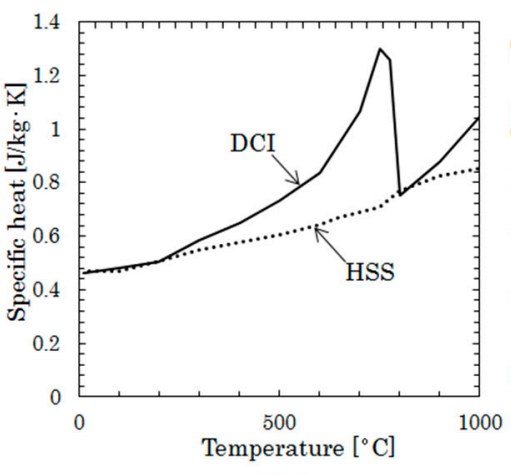

(b)

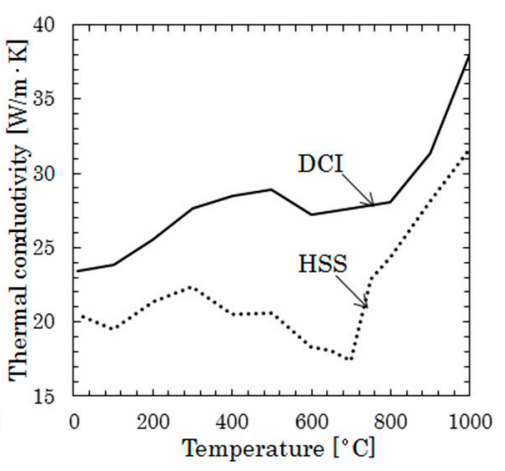

(c)

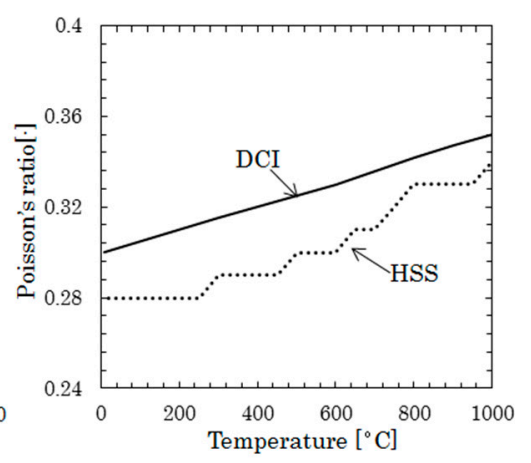

(e)

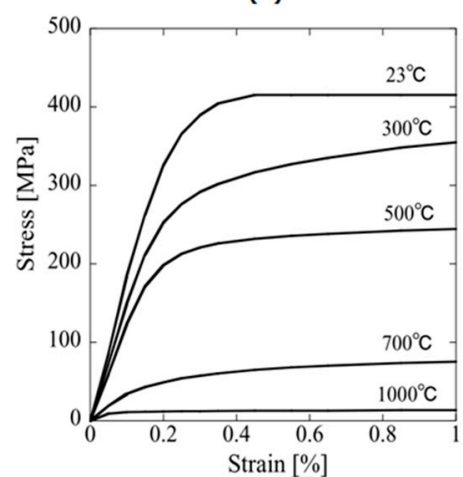

(g)

Figure 3. (a) Young's modulus; (b) specific heat; (c) thermal conductivity; (d) thermal expansion coefficient during quenching; (e) Poisson's ratio; (f) stress-strain for HSS; (g) stress-strain for DCI. 


\section{FEM Modeling}

For the FEM analysis, the software MSC Software's Marc and Mentat 2012 was used to perform the simulation of the quenching process of the bimetallic roll, while the Newton-Raphson strategy was used to solve non-linear equations in an implicit scheme. Figure 4 shows the transient-static simulation model of a half-length of the roll by using a four-node linear axisymmetric quad element with a mesh size of $5 \times 5 \mathrm{~mm}$. Due to the symmetry, the thermal isolation conditions and displacement boundary conditions are applied to $\mathrm{z}=0$. This thermo-elastic plastic material model consists of 17,785 elements with 18,150 nodes and considered the Von Mises yield criterion and isotropic strain hardening rule.

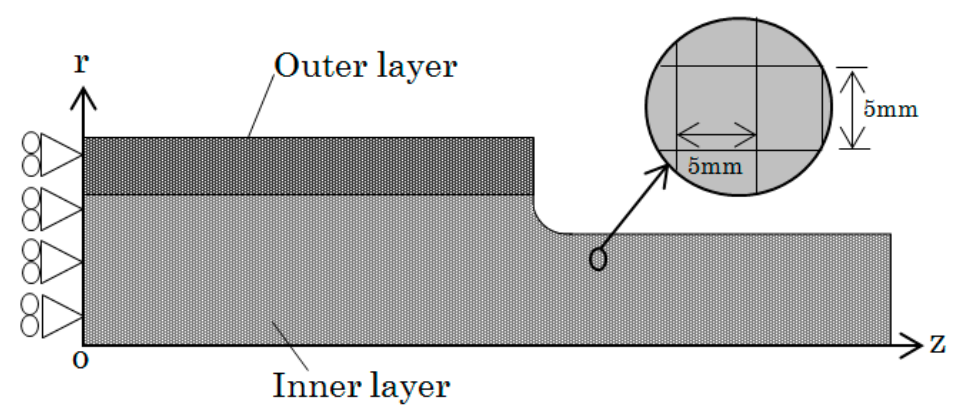

Figure 4. Analytical model and boundary condition for bimetallic roll.

Figure 5 shows the temperature of the roll surface for (a) uniform heating; (b) non-uniform heating. All the material properties were measured experimentally from the initial quenching temperature, $\mathrm{T}_{\text {Start }}$, to the end hardening temperature, $\mathrm{T}_{\text {Finish }}$. These temperature histories are used as the thermal loading to create the residual stress field. Therefore, the thermal strains and stresses for each increment can be calculated.

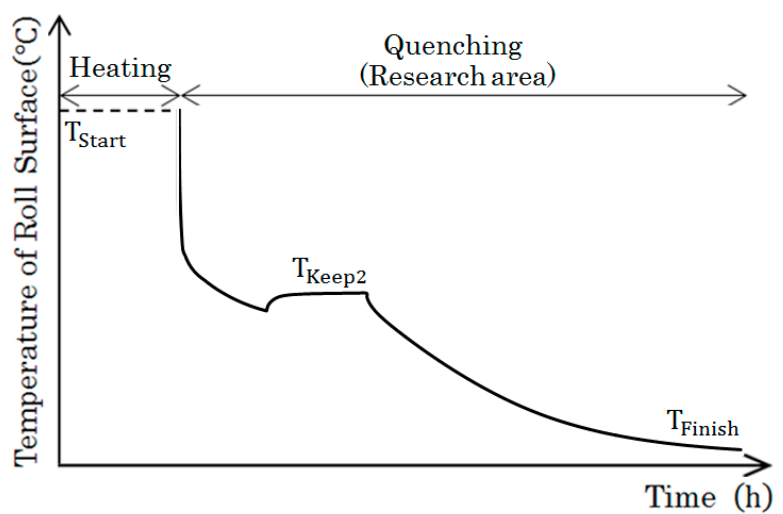

(a)

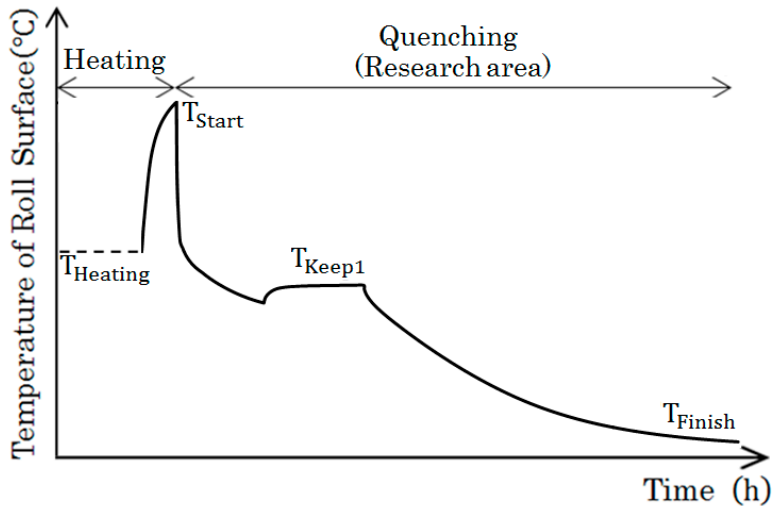

(b)

Figure 5. Schematic diagram of surface temperature for (a) uniform heating; (b) non-uniform heating.

For uniform heating in Figure 5a, the entire work roll was heated up to the quenching start temperature, $\mathrm{T}_{\text {Start }}$. Due to the uniform heating treatment, no residual stress appeared before the quenching process. For non-uniform heating in Figure $5 b$, the entire roll was heated up initially to the pre-quenching temperature, $\mathrm{T}_{\text {Heating }}$. After maintaining this temperature, $\mathrm{T}_{\text {Heating }}$, for a certain time, the roll was rapidly heated up to a higher temperature. Due to this kind of treatment, small residual stress that is less than $30 \mathrm{MPa}$ was found at the early stage of the quenching process. When the surface temperature reached the starting temperature $\mathrm{T}_{\text {Start }}$, a mixed of water and air was discharged from the furnace to start the cooling process. During the cooling, the surface temperature of the roll was maintained at the keep temperature, $\mathrm{T}_{\mathrm{Keep} 1}$, to alleviate the thermal stress accompanying the rapid decrease of the surface temperature. Then, the roll was cooled down slowly to the end temperature, $\mathrm{T}_{\text {Finish. }}$. The stress at this point was treated as the residual stress in this study, although the tempering 
was not completed. In the tempering treatment, the roll was tempered in the furnace after being heated up to the keeping temperature, $\mathrm{T}_{\text {Tempering, }}$ and maintained for a certain time. Then, it was gradually cooled in the furnace to complete the heat treatment.

In the creep analysis, the transient creep strain was considered where the time hardening law was used to express the core material due to its low strength under high temperature. The core creep equation is given as:

$$
\varepsilon_{c}=A \sigma^{m} t^{n}
$$

where $\varepsilon_{c}$ is the transient strain, $\sigma$ is the stress, $t$ is the time, and $A, m$, and $n$ are temperature-dependent material constants. All these unknown constants are determined by performing experimental creep tests [19]. Since the formula was used under constant temperature in the present simulation, this expression of the creep strain depended only on time and stress.

\section{Influence on Residual Stress by Non-Uniform Heating}

By performing non-uniform heating, the surface and center temperatures will be different. As a result, the risk of roll failure can be reduced by decreasing the center tensile residual stress. The other advantages of non-uniform heating quenching are listed as follows:

1. The internal temperature is lower than $900^{\circ} \mathrm{C}$, which contributes to the avoidance of overheating and prevents material deterioration.

2. Due to the rapid cooling of the quenching, a hard shell is obtained, improving the impact strength of the roll.

3. Energy consumption can be reduced because the heating time is shortened.

4. The time and cost of the operation can be also reduced since the time required for heating is shortened.

Figure 6 shows the distribution of the residual stress $\sigma_{z}$ in the central cross-section of the roll. In this thermal analysis, a total of 905 load steps, corresponding to $t=1140 \mathrm{~s}$, were required to complete the heating cycles.

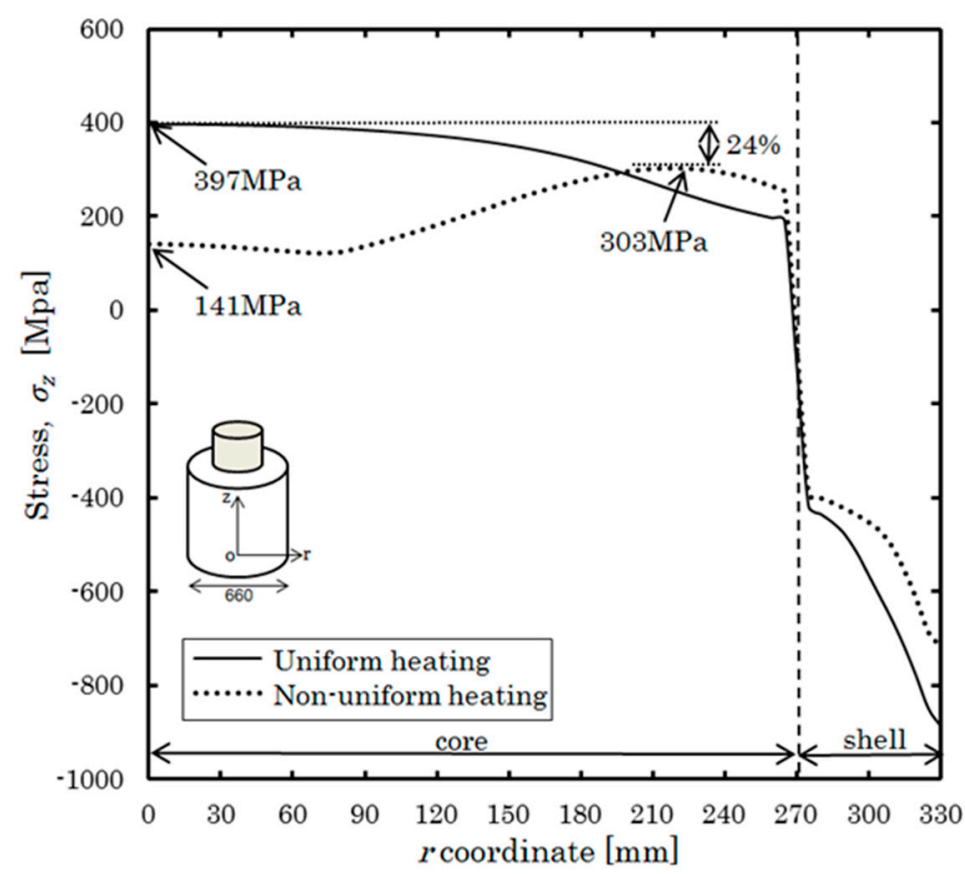

Figure 6. Comparison of residual stress distribution, $\sigma_{z}$, for both heating treatments. 
As shown in Figure 6, the maximum tensile stress for non-uniform heating appearing at the roll center decreased to as low as $141 \mathrm{MPa}$. The compressive residual stress at the surface decreased, but remained sufficiently large enough to guard against thermal crack. Meanwhile, the maximum tensile stress for non-uniform heating was $24 \%$ less than that for uniform heating. From Figure 6, it may be considered that non-uniform heating is efficient in reducing the fracture risk at the roll center without losing the crack prevention ability of the roll surface.

\section{Comparison between Uniform Heating and Non-Uniform Heating}

\subsection{Stress Generation Mechanism of Uniform Heating and Non-Uniform Heating}

Figures 7 and 8 show the results for (a) temperature versus time and (b) corresponding stress, $\sigma_{z}$, versus time for uniform and non-uniform heating processes, respectively.

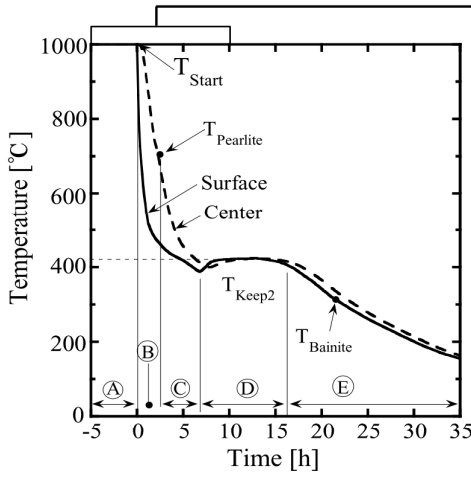

(A) Constant high temperature

(C) Core phase transformation

(E) Slow cooling in furnace

(a)

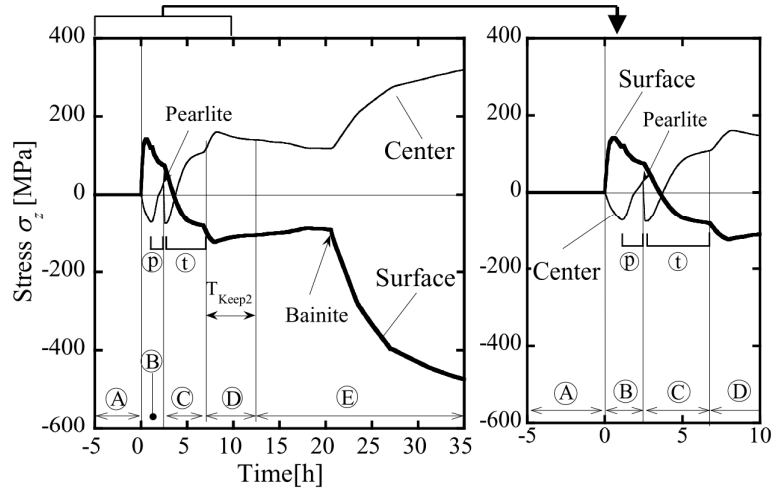

(DEffect of pearlite transformation (1)Effect of temperature

Figure 7. Uniform heating process and corresponding stress, $\sigma_{z}$ : (a) temperature at the center and surface; (b) stress, $\sigma_{z}$, at the center and surface.

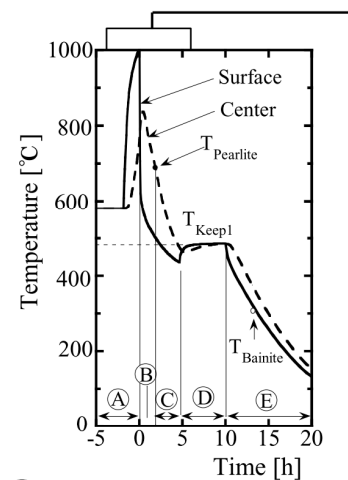

(A) Rapid surface heating

(C) Core phase transformation (D) Hold temperature

(E) Air cooling

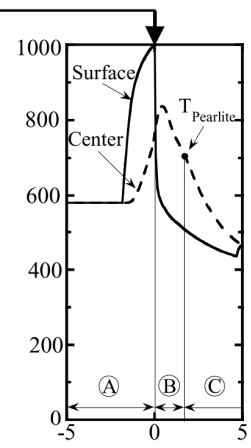

(B) Rapid surface cooling

(a)

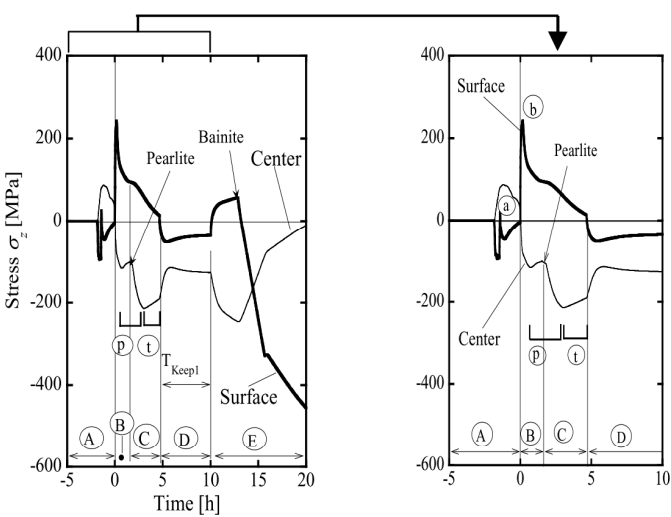

(a) Austenite transformation (b) Peak residual stress at surface

Figure 8. Non-uniform heating process and corresponding stress, $\sigma_{z}$ : (a) temperature at the center and surface; (b) stress, $\sigma_{z}$, at the center and surface.

As shown in Figure 7, the period (A) is a heating process while the periods (B), C), (D), and (E) are the quenching processes. During process (A), no difference can be seen between the center and surface since the roll is heated up uniformly and no stress occurs. During the rapid surface cooling process (B), the tensile stress of the outer layer increases initially due to the cooling shrinkage of the 
outer layer. However, the tensile stress suddenly changes to compressive stress because the thermal shrinkage at the central part becomes larger. Pearlite transformation appears at the inner layer at the pearlitization temperature, $\mathrm{T}_{\text {Pearlite, }}$ which expands from the inner layer boundary toward the roll center. During this process, (B), the center compressive stress decreases until reaching $\mathrm{T}_{\text {Pearlite }}$. During process (C), the pearlite transformation causes the formation of compressive stress at the roll center. Then, the tensile stress at the center with a high cooling rate increases and eventually the stress at the center and the stress at the surface intersect. The compressive stress at the surface and the tensile stress at the center maintain until the temperature $T_{\text {Keep2 }}$ is reached. During the initial temperature keeping period, (D), since the heating is applied to adjust the overcooling at the roll surface, both the surface compressive stress and the center tensile stress increase slightly. After heating, the temperature difference becomes smaller between the surface and the center. During period (E), the surface cooling starts outside the furnace, and the surface temperature decreases. Then, the center tensile stress and the surface compressive stress both increase. During period (E), Bainite expansion transformation occurs at the inner layer at the bainitization temperature, $\mathrm{T}_{\text {Bainite, }}$ promoting the surface compressive stress and the center tensile stress.

As shown in Figure 8, during the non-uniform heating process, (A), the entire roll is heated up initially to the pre-quenching temperature, $\mathrm{T}_{\text {Heating. }}$. After that, the roll surface is rapidly heated up to the roll surface temperature, $T_{\text {Start }}$, while the roll center is heated at a lower temperature in a non-uniform manner. At the early stage of this heating process, tension is generated at the center due to the surface thermal expansion. The surface compressive stress turns into tensile stress due to transformation contraction at the austenitization temperature, $\mathrm{T}_{\text {Austenite }}$. After that, the temperature difference becomes smaller between the surface and the center and both stresses decrease. At the initial stage of quenching, (B), a large tensile stress forms at the surface because of the high cooling speed. The pearlite transformation occurs at the initial stage of (C), and the center compressive stress is maintained. At the initial stage of (D), due to the roll surface heating process, the surface tensile

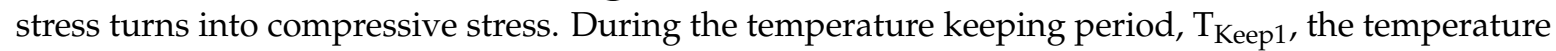
difference becomes smaller between the surface and the center. Then, the stress change is small. During the air-cooling period, (E), Bainite expansion transformation occurs. In the outer layer-similar to the uniform heating case in Figure 7-both the surface compressive stress and the center tensile stress increase.

As shown in Figure 6, the central compressive stress under uniform heating becomes smaller than that under non-uniform heating. This can be explained by the following. During pearlite transformation, $(\mathrm{P}$, in Figures 7 and 8, the stress change under non-uniform heating (indicated as $(\mathrm{P}$ in Figure 8) is smaller than the stress change under uniform heating (indicated as $(\mathrm{P}$ in Figure 7). In a similar way, the central stress increase (indicated as $(t)$ in Figure 8 ) under non-uniform heating is also smaller than the central stress increase (indicated as $(\mathfrak{f}$ in Figure 7) under uniform heating after the pearlite transformation. The effects of the temperature keeping period, (D), and air-cooling period, (E), are nearly the same in Figures 7 and 8. In the non-uniform heating process, the smaller stress increase after the central pearlite transformation results in the reduction of the center tensile stress.

\subsection{Effect of Diameter on Uniform Heating and Non-Uniform Heating}

Figure $9 \mathrm{a}$ shows the residual stress distribution for uniform heating obtained by varying the diameter from $500 \mathrm{~mm}$ to $1000 \mathrm{~mm}$ in increments of $100 \mathrm{~mm}$ with an area ratio of 0.4 . Since the area ratio is fixed, the residual stress of the inner layer can be represented by the stress at the center. At the center, the tensile stress increases by $53 \mathrm{MPa}$ as the diameter changes from $500 \mathrm{~mm}$ to $1000 \mathrm{~mm}$. Meanwhile, Figure $9 \mathrm{~b}$ shows the diameter effect result of non-uniform heating. The result is significant as the real roll diameter used is between $600 \mathrm{~mm}$ to $800 \mathrm{~mm}$. The maximum tensile stress at the inner layer is $261 \mathrm{MPa}$ when the roll diameter is $900 \mathrm{~mm}$. The surface compressive stress varies significantly as the roll diameter changes from $500 \mathrm{~mm}$ to $600 \mathrm{~mm}$. 


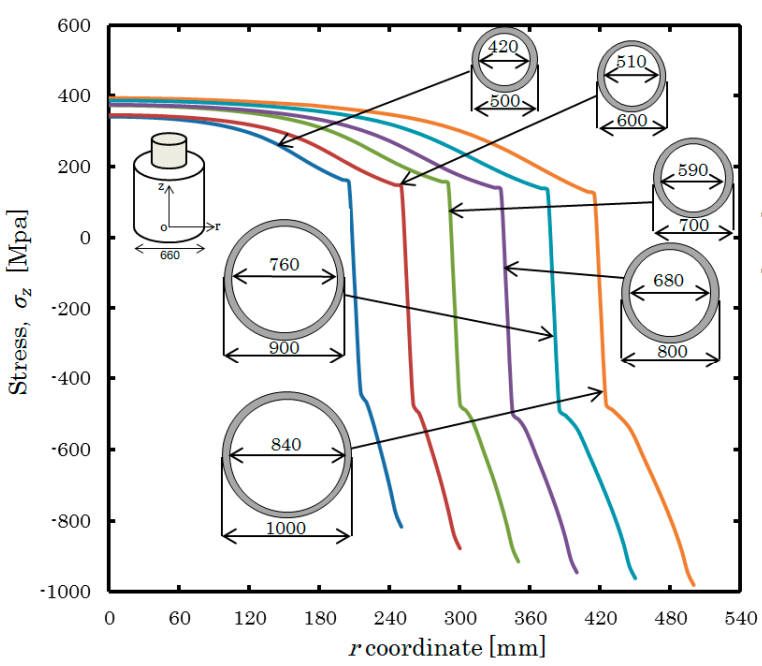

(a)

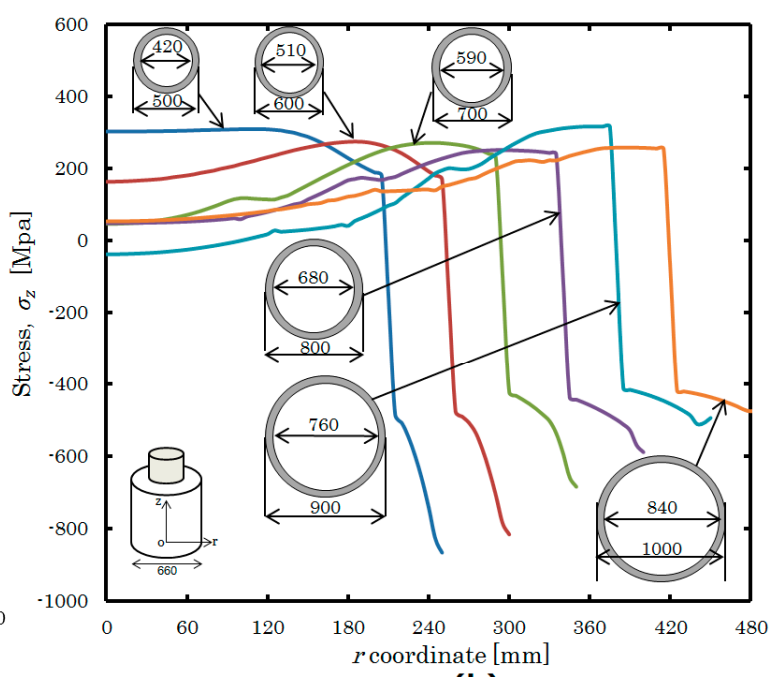

(b)

Figure 9. Residual stress distribution, $\sigma_{z}$, for different diameters. (a) Uniform heating; (b) nonuniform heating.

\subsection{Effect of Area Ratio on Uniform Heating and Non-Uniform Heating}

Figure 10a,b shows the residual stress distribution for different area ratios for uniform and non-uniform heating processes, respectively. The outer roll diameter is fixed as $660 \mathrm{~mm}$. For uniform heating, the center tensile stress increases by $120 \mathrm{MPa}$ as the area ratio changes from 0.2 to 0.8 . Meanwhile, for non-uniform heating, the tensile stress increases by $127 \mathrm{MPa}$ for the same ratios. The compressive stresses at the surface are almost unchanged for both results. The results show that the area ratio only exerts a small influence on the residual stress of the bimetallic roll.

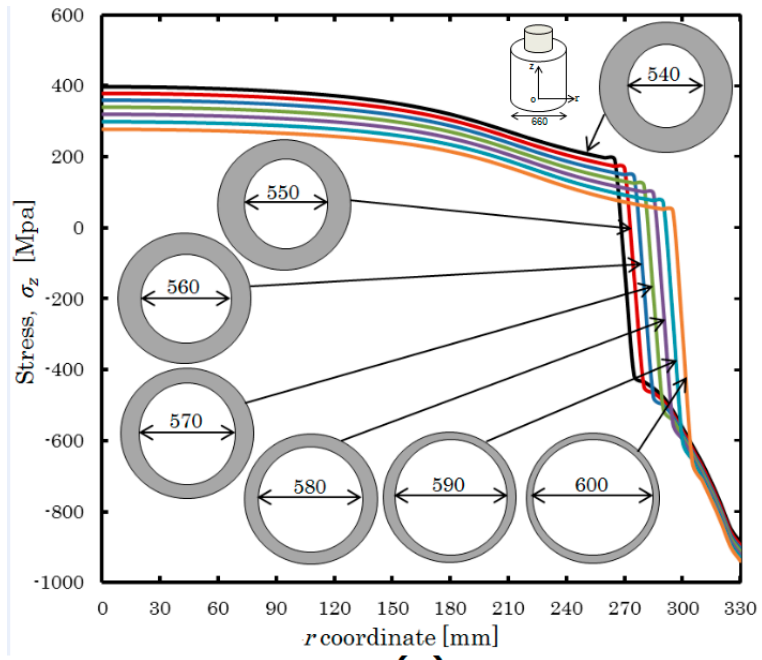

(a)

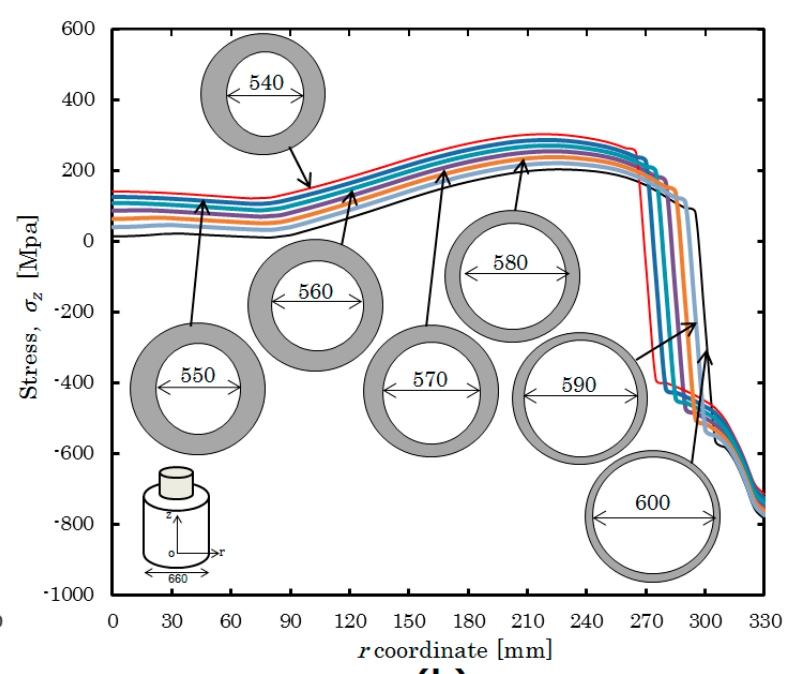

(b)

Figure 10. Residual stress distribution, $\sigma_{z}$, for different area ratios. (a) Uniform heating; (b) nonuniform heating.

\section{Conclusions}

In this study, residual stress was discussed under uniform and non-uniform heating treatments by considering creep behavior. The bimetallic roll tested consisted of high-speed steel at the shell and ductile cast iron at the core. Although a similar study can be found in previous work, no material data 
was indicated. In the current work, all the material data were indicated to provide a detailed view of the effects of material properties on residual stress.

After uniform and non-uniform heating treatments, the quenching process was simulated by applying thermo-elastic plastic finite element method analysis. The conclusions are summarized as follows:

1. The tensile stress of the inner layer after non-uniform heating and quenching was less than that obtained after uniform heating and quenching by $24 \%$, while the compressive stress on the surface for both heating treatments did not differ greatly. As a result, the effect of preventing surface cracking can be expected to reduce damage originating from the center.

2. Based on the stress generation mechanisms, it was found that the stress in the central part decreased by non-uniform heating because during pearlite transformation, (B), the increase in the central stress in non-uniform heating (P) was small. Similarly, the increase in the central stress $(\mathfrak{t})$ in non-uniform heating is also small in region (C) after the pearlite transformation.

3. Based on the diameter effect result, the center tensile stress for non-uniform heating was smaller compared to that for uniform heating. Furthermore, the surface compressive stress varied significantly as the diameter changes from $500 \mathrm{~mm}$ to $1000 \mathrm{~mm}$.

4. The results of the area ratio effect showed that the center tensile stress for non-uniform heating was smaller than that for uniform heating, while the compressive stress at the surface was almost unchanged for both results. In conclusion, the area ratio only exerts a small influence on the residual stress of bimetallic rolls for both heating treatments.

Author Contributions: N.-A.N. supervised the research; Y.S. proposed and advised the research; M.R.A. wrote the paper; K.T. and N.O. performed the FEM simulation.

Funding: This research received no external funding.

Conflicts of Interest: The authors declare no conflict of interest.

\section{References}

1. Goto, K.; Matsuda, Y.; Sakamoto, K.; Sugimoto, Y. Basic characteristics and microstructure of high-carbon high speed steel rolls for hot rolling mill. ISIJ Int. 1992, 32, 1184-1189. [CrossRef]

2. Belzunce, F.J.; Ziadi, A.; Rodriguez, C. Structural integrity of hot strip mill rolling rolls. Eng. Fail. Anal. 2004, 11, 789-797. [CrossRef]

3. Spuzic, S.; Strafford, K.N.; Subramanian, C.; Savage, G. Wear of hot rolling mill rolls: An overview. Wear 1994, 176, 261-271. [CrossRef]

4. Park, J.W.; Lee, H.C.; Lee, S. Composition, microstructure, hardness, and wear properties of high-speed steel rolls. Metall. Mater. Trans. A 1999, 30, 399-409. [CrossRef]

5. Sedlaček, M.; Podgornik, B.; Milanovič, S. A modified heat treatment to improve the properties of double layer cast rolls. Mater. Technol. 2014, 48, 983-990.

6. Lee, J.H.; Oh, J.C.; Park, J.W.; Lee, H.C.; Lee, S. Effects of tempering temperature on wear resistance and surface roughness of a high speed steel roll. ISIJ Int. 2001, 41, 859-865. [CrossRef]

7. Fu, H.; Xiao, Q.; Xing, J.D. A study on the crack control of a high-speed steel roll fabricated by a centrifugal casting technique. Mater. Sci. Eng. A 2008, 474, 82-87. [CrossRef]

8. Noda, N.-A.; Hu, K.; Sano, Y.; Hosokawa, Y.; Wang, X. Accuracy of disk method to predict roll residual stress by measuring the sliced disk stress. ISIJ Int. 2017, 57, 1432-1440. [CrossRef]

9. Li, C.S.; Yu, H.L.; Deng, G.Y.; Liu, X.H.; Wang, G.D. Numerical simulation of temperature field and thermal stress field of work roll during hot strip rolling. J. Iron Steel Res. Int. 2007, 14, 18-21. [CrossRef]

10. Benasciutti, D.; Brusa, E.; Bazzaro, G. Finite elements prediction of thermal stresses in work roll of hot rolling mills. Procedia Eng. 2010, 2, 707-716. [CrossRef]

11. Park, C.M.; Kim, W.S.; Park, G.J. Thermal analysis of the roll in the strip casting process. Mech. Res. Commun. 2003, 30, 297-310. [CrossRef] 
12. Sakai, K. Calculation of thermal stress in cylindrical steel during cooling. Tetsu-to-Hagane 1974, 60, 1591-1598. [CrossRef]

13. Yin, Y.Z.; Wang, Y.Z. Numerical simulations of the effects of non-uniform temperature distributions on lateral torsional buckling resistance of steel I-beams. J. Constr. Steel Res. 2003, 59, 1009-1033. [CrossRef]

14. Inoue, T.; Haraguchi, K.; Kimura, S. Stress analysis during quenching and tempering. J. Soc. Mater. Sci. Jpn. 1976, 25, 521-526. [CrossRef]

15. Isomura, R. Residual stresses in heat-treated steels. Tetsu-to-Hagane 1961, 47, 936-950. [CrossRef]

16. Acevedo, C.; Nussbaumer, A. Effect of tensile residual stresses on fatigue crack growth and $S-N$ curves in tubular joints loaded in compression. Int. J. Fatigue 2012, 36, 171-180. [CrossRef]

17. Noda, N.-A.; Hu, K.; Sano, Y.; Ono, K.; Hosokawa, Y. Residual stress simulation for hot strip bimetallic roll during quenching. Steel Res. Int. 2016, 87, 1478-1488. [CrossRef]

18. Noda, N.-A.; Sano, Y.; Xu, W.; Nakagawa, Y.; Guan, W.; Ono, K.; Hu, K. Residual stress simulation and generation mechanism for hot strip composite roll during the quenching. Trans. Soc. Autom. Eng. Jpn. 2015, $46,831-837$.

19. Noda, N.-A.; Hu, K.; Sano, Y.; Ono, K.; Hosokawa, Y. Usefulness of non-uniform heating and quenching method for residual stress of bimetallic roll: FEM simulation considering creep behavior. Steel Res. Int. 2017, 88, 1600165. [CrossRef]

(C) 2018 by the authors. Licensee MDPI, Basel, Switzerland. This article is an open access article distributed under the terms and conditions of the Creative Commons Attribution (CC BY) license (http:/ / creativecommons.org/licenses/by/4.0/). 